\title{
O ENVELHECER NO MEIO RURAL: OS IDOSOS E IDOSAS DO ASSENTAMENTO MILTON SANTOS - AMERICANA - SP
}

\author{
Danitielle Cineli Simonato ${ }^{1}$ \\ Sonia Maria Pessoa Pereira Bergamasco²
}

\begin{abstract}
RESUMO
O objetivo do presente trabalho foi proceder a uma leitura do processo de envelhecimento dos idosos rurais em um Assentamento de Reforma Agrária do município de Americana - SP. A pesquisa foi realizada com oito (8) idosos (as) e foi ancorada numa abordagem qualitativa com o uso da entrevista semiestruturada amparada por um roteiro que versou sobre a origem dos idosos, as condições de vida, a aposentadoria, a renda, os arranjos familiares, o grau de escolaridade e o acesso à saúde. Para além, pesquisou-se questões mais subjetivas como as estratégias de vida e luta pela terra e a qualidade de vida no meio rural. $O$ estudo foi realizado entre os meses de março a maio de 2015. A análise dos resultados permitiu observar que a aposentadoria, e o acesso aos serviços de saúde são grandes gargalos para este público. Por outro lado, a maioria dos idosos (as) ainda são responsáveis pela condução dos lotes e outro ponto positivo está na presença do Programa de Educação de Jovens e Adultos (EJA). Por fim, faz-se necessária atenção sobre o envelhecimento no meio rural com programas e políticas públicas específicas a este público, a questão da sucessão da terra e o futuro da agricultura familiar.
\end{abstract}

Palavras Chaves: Reforma agrária, envelhecimento, população rural.

\section{AGING IN THE RURAL ENVIRONMENT: CASE STUDY OF MILTON SANTOS RURAL SETTLEMENT - AMERICANA - SP}

\begin{abstract}
The aim of this study was to read the aging process of rural elderly in an Agrarian Reform Settlement in the city of Americana - SP. The research was carried out with eight (8) elderly people and was anchored in a qualitative approach using semistructured interviews supported by a script that addressed the origin of the elderly, living conditions, retirement, income, arrangements family members, educational level and access to health. In addition, more subjective issues were researched, such as the strategies of life and struggle for land and the quality of life in rural areas. A survey was carried out between March and May 2015. The analysis of the results observed that retirement, and access to health services are major bottlenecks for this public. On the other hand, most of the elderly are still responsible for conducting the lots and another positive point is in the presence of the Youth and Adult Education Program

${ }^{1}$ Graduada em Ciências Biológicas (UNESP). Mestrado em Agroecologia e Desenvolvimento Rural (UFSCAR). Doutorado em Engenharia Agrícola (UNICAMP). E-mail: dani_simonato@yahoo.com.br.

2 Graduada em Agronomia (USP). Mestrado em Extensão Rural (UFV). Doutorado em Ciências (UNESP).

Professora Titular da Faculdade de Engenharia Agrícola (UNICAMP). E-mail:soniaberga@yahoo.com.
\end{abstract}


(EJA). Finally, attention is needed on aging in rural areas with programs and public policies specific to this public, the issue of land succession and the future of family farming.

Keywords: Land reform, aging, rural population.

\title{
1. INTRODUÇÃO
}

O envelhecimento populacional vem modificando a estrutura de toda a sociedade, sendo este fenômeno um grande avanço e uma conquista social a ser celebrada, como também nos coloca frente a desafios no presente e no futuro. Estas mudanças ocorrem na dinâmica demográfica dos países suscitando alterações significativas nas pirâmides etárias, redesenhando-as e invertendo-as, ou seja, com o passar dos anos suas bases vêm diminuindo ao passo que seu topo está aumentando gradativamente.

Este envelhecimento traz no âmago da sociedade um novo sujeito: os idosos e idosas e se faz urgente compreender as demandas desta nova categoria social. Segundo a Política Nacional do Idoso (PNI), Lei no8. 842, de 4 de janeiro de 1994, e o Estatuto do Idoso, Lei ํㅜ 10.741, de $1^{\circ}$ de outubro de 2003, definem idosos (as) como pessoas com idade igual ou superior a 60 anos (BRASIL, 1994; 2003).

O mesmo critério/recorte cronológico é utilizado pela Organização Mundial da Saúde (OMS) (2002) que definem idosos (as) como a pessoa acima de 60 anos no caso de países em desenvolvimento e acima de 65 anos em países desenvolvidos. Embora o recorte cronológico seja o mais utilizado é preciso compreender que ser idoso ou idosa se define como um termo muito mais complexo que perpassa aspectos biológicos, psicológicos, sociológicos, culturais, ou seja, multifatorial, apesar de cada indivíduo experimentar esta fase da vida de acordo com o seu histórico de vida e seus multifatores, este se apresenta como um fenômeno de ordem coletiva.

Estudos reafirmam esta complexidade de se definir o que é idoso (a):

\begin{abstract}
Apesar de ser dos menos preciso, o critério cronológico é um dos mais utilizados para estabelecer o ser idoso, até na delimitação da população de um determinado estudo, ou análise epidemiológica, ou com propósitos administrativos e legais voltados para desenho de políticas públicas e para o planejamento ou oferta de serviços. Os fenômenos do envelhecimento e da velhice e a determinação de quem seja idoso (a), muitas vezes, são considerados com referência às restritas modificações que ocorrem no corpo, na dimensão física. Mas é desejável que se perceba que, ao longo dos anos, são processadas mudanças também na forma de pensar, de sentir e de agir dos seres humanos que passam por esta etapa do processo de viver. Complemento, acrescentando que o ser humano idoso (a) tem várias dimensões: biológica, psicológica, social, espiritual e outras, que necessitam ser consideradas para aproximação de um conceito que o abranja e que o perceba como ser complexo (SANTOS, 2010, p.1036).
\end{abstract}

Em termos numéricos, dados do relatório "World Population Prospects, 2019" do Departamento para Assuntos Sociais e Econômicos das Organização das Nações Unidas (ONU) retratam os números da população idosa mundial, ou seja, acima de 
pessoas acima de 60 anos chegou a 1,1 bilhão de pessoas no mundo e a região da América Latina e Caribe somam mais de 75 milhões de idosos (as) (ONU, 2019).

Dados mais recentes do Instituto Brasileiro de Geografia e Estatística (IBGE) através da Pesquisa Nacional por Amostra de Domicílios (PNAD) (2019) compilados pelo Departamento Intersindical de Estatística e Estudos Socioeconômicos (DIEESE) do ano de 2019 demonstram que a população total do Brasil já alcança 210,1 milhões de pessoas, onde, 34 milhões são idosos e idosas o que corresponde a 16,2\% da população do país (DIEESE, 2020).

Compreender este crescente e acelerado contingente de pessoas acima de 60 anos nos faz pensar em parâmetros principais que ilustram estas transformações que são elas: a taxa de fecundidade, a taxa de mortalidade e a expectativa de vida ao nascer. A taxa de fecundidade diz muito sobre a dinâmica da população, pois mede a sua recomposição, ou seja, mede o número médio de filhos nascidos vivos que uma mulher teria ao fim do seu período reprodutivo. Neste quesito, entre os anos de 2005 e 2018 a taxa de fecundidade no Brasil caiu de 2,09 filhos por mulher para 1,77 filhos por mulher. Por sua vez, a taxa de mortalidade é um componente demográfico que explica o número de mortes, em média, por mil habitantes. Em 2005, a taxa de mortalidade era de 6,20 por mil/hab., em 2015, 6,08 por mil/hab. Por último, a expectativa de vida ou esperança de vida ao nascer é um componente demográfico que consiste na estimativa do número de anos que se espera que um indivíduo possa viver. A expectativa de vida para o brasileiro passou de 72,0 anos em 2005 para 76 anos em 2017 (IBGE, 2020).

Este aumento da longevidade da população brasileira advém de vários fatores como: melhoria do saneamento básico, avanços no sistema de saúde como o programa de Estratégia de Saúde da Família (ESF), melhoria no processo de imunização (vacinação) e tecnologia em saúde com diagnósticos mais rápidos e eficientes. Melhoria nas condições socioeconômicas com acesso universalizado à aposentadoria com a Constituição Federal de 1988, na questão cultural um maior protagonismo dos idosos (as) dentro da sociedade e não só como "peso" no sistema econômico, bem como evolução do aparato legislativo (leis) reconhecendo os direitos dos idosos (as) desde a esfera federal, estadual e municipal.

Diante do cenário e das evoluções desencadeadas na sociedade brasileira, quando voltamos os olhares ao meio rural e seu envelhecimento precisamos alimentar esta cena com mais elementos para compreensão de toda a realidade. Primeiro o êxodo rural que levou mais de 27 milhões de pessoas a saírem do campo para a cidade entre as décadas de 1960 a 1980 (CAMARANO e ABRAMOVAY, 1999).

Em estudo semelhante sobre envelhecimento rural Boscardin e Spanevello (2018) apontam a Revolução Verde e a Modernização da Agricultura também como fatores determinantes para a saída da população do campo para a cidade entre as décadas de 1950 a 1970. Estes dois processos incorporaram modernos pacotes tecnológicos visando a produtividade, a incorporação de insumos e maquinários agrícolas. Isto causou uma redução drástica da demanda por mão de obra no campo, ao mesmo tempo que o meio urbano e o crescimento vertiginoso das cidades demandavam mão de obra para as indústrias, especialmente, mão de obra jovem contribuindo para o êxodo rural.

Embora se constate nos últimos anos um número decrescente de pessoas vivendo no campo, há que se considerar a importância desta população e toda sua diversidade, principalmente, quando se voltarmos nossos olhares a agricultura familiar brasileira, sendo composta por: indígenas, quilombolas, agricultores familiares tradicionais, arrendatários e assentados rurais, este último, sendo interesse do trabalho, tendo em conta suas peculiaridades a luta pela terra. Assim sendo, verificase a necessidade de estudos e pesquisas acadêmicas que abordem a temática do 
envelhecimento e suas implicações no meio rural, sobretudo em assentamentos rurais, que se constituíram a partir da luta pela terra, tornando-se um importante espaço de produção agrícola, reprodução social, econômica e política (LEITE, 2004).

Dados da PNAD (2013) afirmam que do total da população idosa no Brasil, os idosos rurais são estimados em $15,7 \%$ e $84,3 \%$ no meio urbano. Dados mais recentes do Censo Agropecuário do IBGE (2017) apontam que dos 5.072.152 estabelecimentos agropecuários existentes no Brasil, 1.729.653 estabelecimentos agropecuários já se encontram nas mãos de pessoas acima de 60 anos de idade, 0 que corresponde a $34 \%$ do total.

Se os estudos sobre os idosos (as) no meio rural são escassos, mais raro ainda são os estudos sobre os idosos (as) e seu processo de envelhecimento em Assentamentos de Reforma Agrária, objeto do presente estudo.

Um dos poucos estudos sobre os idosos em Assentamentos Rurais é o de Gonzaga et al. (2014) que afirma:

\begin{abstract}
Os idosos e idosas, vêm historicamente desenvolvendo o trabalho na terra, como camponeses/as que lutam para preservar sua identidade...são pessoas que viram na terra uma oportunidade de melhorar de vida, lutando como acampados e posteriormente assentados rurais. São trabalhadores/as que vivem da produção da terra, acumulando conhecimentos e experiências, que permeiam as diferentes gerações, ao mesmo tempo que resistem ao sistema através da produção de auto sustentação e da manutenção de valores comunitários e familiares. Ao mesmo tempo, inserem-se na sociedade atual, marcada pela aculturação da imagem negativa da velhice, acarretando o não reconhecimento de que são velhos. São frutos de uma realidade de consciência construída, a partir de seu meio e realidade, diante de sua história de contradições e da forma como vivenciam o seu processo de transformação e autotransformação (GONZAGA et al., 2014, p.07).
\end{abstract}

Em uma pesquisa realizada pelo Instituto Nacional de Colonização e Reforma Agrária (INCRA) sobre a Qualidade de Vida, Produção e Renda dos Assentamentos da Reforma Agrária (PQRA), (INCRA, 2010), concluiu-se que da população total residente nos Assentamentos brasileiros, cerca de 7,55 \% já possuem mais de 60 anos.

Assim, o objetivo do presente estudo foi proceder a uma leitura do processo de envelhecimento no meio rural, em específico, em um Assentamento Rural, a fim de conhecermos as condições de vida e o bem estar, a questão da seguridade social, a luta pela terra, os sonhos e as perspectivas, a produção agropecuária e a rede de apoio que os cercavam.

\title{
2. CAMINHOS METODOLÓGICOS
}

A presente pesquisa foi realizada entre os meses de março a maio do ano de 2015 no Assentamento Milton Santos, localizado no município de Americana, região leste do Estado de São Paulo. O assentamento foi homologado em 2005 e está sob jurisdição do INCRA. É composto atualmente por 68 famílias, estima-se que a população do assentamento esteja em torno de 280 pessoas $^{3}$. A área total é de (104 ha), cada lote apresenta uma área de (1 ha), sendo em Reserva Legal (20,88 ha),

\footnotetext{
${ }^{3}$ Essas informações foram coletadas em 2020 com a ex-liderança do Assentamento Milton Santos.
} 
Área de Preservação Permanente (10,88 ha) e Área Agrícola (71,84 ha), esta área agrícola consiste em uma área coletiva de produção dividida entre os núcleos de famílias do assentamento, como será explicitada ao longo do texto.

O assentamento foi criado a partir de uma portaria do INCRA através da Portaria n 477/99, estabelecendo o "Projeto de Desenvolvimento Sustentável" (PDS). Esta modalidade de assentamento consiste em áreas de interesse ambiental para práticas agrícolas mais sustentáveis baseadas na Agroecologia. Outra experiência concebida no Assentamento Milton Santos foi a Comuna da Terra, este modelo de assentamento vislumbrado pelo Movimento dos Trabalhadores Rurais Sem Terra (MST), se destina à pessoas que residem em grandes centros urbanos ou periferias das grandes cidades ou regiões metropolitanas, que possuem um passado ligado à terra que utilizarão a Agroecologia e a cooperação como bases na produção, visando melhoria da renda, a segurança alimentar e nutricional das famílias e o combate à pobreza, além da oferta de alimentos saudáveis, baratos e mais próximos as cidades, isto é, criando circuitos curtos e sustentáveis de comercialização destes redutos rurais às cidades (MATHEUS, 2003; GOLDFARB, 2007).

Diante desta concepção que foi formatado o assentamento, as famílias se organizaram em sete (7) núcleos sendo eles denominados: Che Guevara, Olga Benário, Terra Prometida, Recanto Feliz, Solo Sagrado, Margarida Alves e Eldorado. Estes núcleos possuem um coordenador (a) escolhido entre os pares, a fim de se organizarem na produção agrícola da área agrícola coletiva, dentre as outras demandas de cunho coletivo dos núcleos (SILVA, 2007).

De modo geral, a produção do assentamento está baseada em itens como: mandioca, batata doce, alface, rúcula, berinjela, jiló, milho, feijão, feijão guandu, feijão de corda, além de produção de pequenos animais para consumo e venda direta como galinha caipira e porcos. As estratégias de comercialização se baseiam em cestas agroecológicas para vendas semanais em grupos de consumo, feiras livres na cidade de Americana, Cosmópolis e Campinas, a venda direta no lote e, por fim, entrega da produção para o Programa de Aquisição de Alimentos (PAA) - Modalidade Doação Simultânea.

\subsection{ETAPAS DA PESQUISA}

Este trabalho começou a ser construído dentro do curso de Especialização "Educação do Campo e Agroecologia na Agricultura Familiar e Camponesa Residência Agrária", da Faculdade de Engenharia Agrícola - Universidade Estadual de Campinas (Feagri/Unicamp) idealizado pelo Programa Nacional de Educação na Reforma Agrária (PRONERA) e com financiamento do Conselho Nacional de Desenvolvimento Científico e Tecnológico (CNPq). Este curso se estabeleceu através da Pedagogia da Alternância que consistia em dois tempos distintos: o Tempo Comunidade e o Tempo Escola ${ }^{4}$.

Durante as idas e vindas a campo nos Tempos Comunidade por diversos assentamentos rurais do Estado de São Paulo notou-se a quantidade de pessoas acima de 60 anos no meio rural, diante disso, voltou-se o olhar a este público dos

\footnotetext{
${ }^{4}$ Os Projetos de Residência Agrária em nível de Especialização Lato Sensu são desenvolvidos conforme a metodologia da alternância, normatizada pela Resolução CNE/CEB n.ำ 01/2006, caracterizada por dois momentos: tempo de estudo desenvolvido nos centros de formação (Tempo Escola - $70 \%$ da carga horária do curso) e o tempo de estudo desenvolvido na comunidade (Tempo Comunidade - $30 \%$ da carga horária do curso). A proposta metodológica deverá fundamentar-se nos instrumentos e estratégias que serão utilizadas para a construção do conhecimento a partir de aspectos da realidade do campo brasileiro, bem como a estratégia inter ou transdisciplinar que facilitará o diálogo entre as áreas do conhecimento e o acúmulo teórico da metodologia da Alternância. Fonte: Manual de Operações do Pronera - 2014.
} 
assentamentos rurais. A escolha pelo Assentamento Milton Santos se deu por este fazer parte do núcleo de Campinas ${ }^{5}$.

Em termos iniciais quisemos saber mais sobre a origem dos mesmos, a questão das condições de vida, a aposentadoria, a renda, os arranjos familiares, o grau de escolaridade e o acesso à saúde, além de questões mais subjetivas como as estratégias de vida e luta pela terra e a qualidade de vida no meio rural. Desta maneira, optou-se por uma abordagem qualitativa, onde o instrumento de pesquisa a ser utilizado foi a entrevista semiestruturada amparada por um roteiro.

Para Richardson (2015), o enfoque qualitativo não emprega um instrumento estatístico, cheio de métricas, mas busca compreender a natureza de um fenômeno social. Assim, reitera que as pesquisas de cunho qualitativo:

descrevem a complexidade de um determinado problema, analisa a interação de várias variáveis, compreende e classifica processos dinâmicos vividos por grupos sociais, contribui no processo de mudança de determinado grupo e possibilita em maior nível de profundidade, o entendimento das particularidades do comportamento dos indivíduos (RICHARDSON 2015, p. 80).

Com relação a opção pela entrevista Gil (2007), declara que:

\begin{abstract}
a entrevista é uma interação social, um diálogo assimétrico e um dos instrumentos de pesquisa mais utilizados nas Ciências Sociais por ser uma técnica que possui certa flexibilidade, e tem por objetivo obter informações sobre o que as pessoas sabem, sentem, creem, fazem, pretendem, razões pessoais, etc.
\end{abstract}

O contato inicial e a inserção junto ao Assentamento foram feitos através da liderança do MST. Esta liderança nos apresentou o assentamento desde a história de luta pela terra, a produção, as dificuldades, a infraestrutura, entre outras questões. Em seguida, em uma de nossas visitas apresentamos os objetivos de nossa pesquisa, onde a mesma indicou os possíveis idosos e idosas que poderíamos conversar, na época nos foram indicados em torno de 15 idosos e idosas no assentamento. Embora nossa intenção não era fazer uma pesquisa quantitativa, nossa amostra ficou em torno de $50 \%$ de idosos e idosas do total.

A abordagem e a maneira que conduzimos a coleta das entrevistas foi estabelecendo uma conversa espontânea, um bate papo, uma prosa. De começo muitos estavam desconfiados (as), até resistentes, no entanto, com o passar do tempo eles e elas foram se sentindo à vontade. A duração das entrevistas variou muito, desde quarenta minutos a uma hora e meia, por isso nossa estratégia estava em marcar dia e hora com os idosos e idosas e reservávamos cerca de um período do dia para cada uma das entrevistas.

Desta forma, foram entrevistados oito (8) idosos e idosas, sendo cinco homens e três mulheres com idades que variaram entre 60 a 77 anos. Estas entrevistas foram transcritas e, por conseguinte, selecionadas os trechos mais relevantes de acordo com os objetivos traçados.

As entrevistas foram realizadas com a permissão desses atores, garantindoIhes sigilo quanto à identificação dos informantes. Em função disto, nas citações do

\footnotetext{
${ }^{5} \mathrm{O}$ curso foi dividido em núcleos regionais: Botucatu, Jaboticabal, Itapetininga e Campinas e abarcava os respectivos assentamentos de cada região, sendo 19 no total. O Assentamento Milton Santos estava dentro do núcleo Campinas.
} 
texto os idosos (as) foram identificados como "Idoso1", "Idoso 2" e assim sucessivamente.

\section{RESULTADOS E DISCUSSÃO}

O perfil dos idosos (as) entrevistados (as), são apresentados no quadro 1.

Quadro 1 - Perfil dos Idosos Pesquisados, Assentamento Milton Santos, 2015.

\begin{tabular}{|c|c|c|c|c|c|}
\hline Identificação & Idade & Sexo & Estado Civil & Escolaridade & Religião \\
\hline Idosa 1 & 62 & $\mathrm{~F}$ & Casada & $\begin{array}{l}\text { Ensino Fundamental } \\
\text { Incompleto }\end{array}$ & Evangélica \\
\hline Idosa 2 & 65 & $\mathrm{~F}$ & Casada & Analfabeta & Evangélica \\
\hline Idosa 3 & 69 & $\mathrm{~F}$ & Viúva & Analfabeta & Evangélica \\
\hline Idoso 4 & 77 & $\bar{M}$ & Casado & Analfabeto & Católico \\
\hline Idoso 5 & 61 & $\bar{M}$ & Casado & $\begin{array}{l}\text { Ensino Fundamental } \\
\text { Incompleto }\end{array}$ & Evangélico \\
\hline Idoso 6 & 70 & M & Casado & Analfabeto & Católico \\
\hline Idoso 7 & 60 & $M$ & Casado & $\begin{array}{l}\text { Ensino Fundamental } \\
\text { Incompleto }\end{array}$ & Evangélico \\
\hline Idoso 8 & 67 & $\mathrm{M}$ & Casado & Analfabeto & Católico \\
\hline
\end{tabular}

Fonte: Dados da Pesquisa, 2015.

Quanto à origem destes assentados, a maioria possui em sua trajetória de vida um contexto de migração, ou seja, são provenientes de outros Estados do Brasil como: Bahia, Pernambuco, Paraná, Sergipe, Mato Grosso, além de três idosos (as) advindos de várias cidades do interior Estado de São Paulo para a região de Americana/Campinas. Estes vieram quando crianças, ou já na fase adulta, muitos vieram sozinhos ou com seus familiares em busca por melhores condições de vida e trabalho.

Em relação à ocupação/trabalho dos idosos (as) pesquisados: dois disseram que antes de se tornarem assentados trabalhavam no corte de cana de açúcar na região de Americana, outros três trabalhavam na construção civil como pedreiros e serventes de pedreiros. Com relação as mulheres idosas entrevistadas antes de se tornarem assentadas rurais, todas exerciam atividades na área urbana como empregadas domésticas ou diaristas.

Em relação à religiosidade, registrou-se que cinco idosos (as) se denominavam Evangélicos e três Católicos, este dado se torna importante ao associarmos a religiosidade, ao bem estar emocional, conforto e amparo psicológico para momentos difíceis, conferindo-lhes um contato com o místico e o sagrado, buscando bem estar e esperança, estes quesitos melhoram, significativamente, a qualidade de vida desses idosos e idosas.

Ademais, a participação e integração destes idosos (as) a grupos formais ou informais de caráter religioso é fundamental para a interação e participação social. Estudos de Oliveira e Rodrigues (2010), afirmam que interagir socialmente nesta fase da vida torna-se essencial no que se diz respeito à qualidade de vida destes atores. Para tanto, com o passar do tempo e tendo as vezes a saúde como um fator limitante de participação social e comunitária, sabe-se que a devoção religiosa traz a essas pessoas sentimentos de auto aceitação, satisfação, consolo, crescimento pessoal e espiritual e promoção do bem estar (CARDOSO; FERREIRA, 2009).

Interessante observar que o Assentamento Milton Santos possui cinco templos religiosos, sendo apenas um católico, localizado na sede do Assentamento, 
onde são realizadas missas mensais, os outros templos são de denominação cristã protestante, dois destes construídos dentro dos lotes dos próprios assentados.

Durante a pesquisa indagamos aos idosos sobre a renda mensal e a aposentadoria. A renda dos assentados se compunha pela venda da produção nos lotes (verduras em geral e pequenos animais como porcos e galinhas) entre vizinhos de lote e na cidade em bairros próximos ao assentamento.

Apenas três, dos oito entrevistados, conseguiram o benefício da aposentadoria. Os outros cinco assentados que ainda não conseguiram, alegaram que o principal entrave é a burocracia, além do valor alto dos honorários pagos a advogados. Destaca-se a seguir a fala dos entrevistados salientando estas dificuldades:

Olha, eu já fui no INSS, já fui lá ver, mas não deu certo porque eu não tinha meu tempo completo de serviço.

Eu não tinha contribuição. Quando tinha... quando era... 12 anos, aí passou para 16.

Entendeu? Quando era 12 anos (e) 55 anos, eu fui atrás, eu fui até no advogado, mas não resolveu nada. Só toma dinheiro da gente (Idoso 2).

Olha eu estou aposentado, isso é minha renda. Daqui do sítio não tiro nada...agradeço o Lula pela aposentadoria, consegui na época dele. Trabalhei muito nessa vida, imagina moça se eu ficasse sem dinheiro. (Idoso 8).

Para os assentados que ainda não conseguiram o benefício à situação é precária, pois suas rendas ficam em menos de um salário mínimo por mês. Uma reivindicação importante feita durante a pesquisa foi a de que os assentados gostariam de receber mais orientações e acompanhamento técnico (a) para o processo de aposentadoria por parte do Instituto BioSistêmico (IBS), instituição que tinha a responsabilidade de prestar o serviço de Assistência Técnica e Extensão Rural (ATER) à época. Muitos alegaram que até recebem orientações, porém quando chegam ao Instituto Nacional do Seguro Social (INSS) à história muda e, por muitas vezes, são tratados com discriminação e preconceito.

Beltrão et al. (2000), analisando a situação da população rural brasileira com respeito à previdência social, constataram que apesar do benefício previdenciário ter a função específica de servir como seguro contra perda de capacidade laboral, é inegável a importância da previdência rural na elevação da renda no campo e, consequentemente, na diminuição da pobreza.

A questão da previdência social rural trouxe para os idosos (as) a chance de permanência no campo, diminuindo a saída destes indivíduos do meio rural. Em relação à aposentadoria, esta proporcionou transformações, nos padrões de consumo dos idosos (as) por vezes, mudanças no modo de vida, uma melhoria significativa de qualidade de vida, dando-os a ideia de protagonismo frente à vida.

Ainda com relação à aposentadoria, hoje, muitos idosos (as) são considerados os "chefes da família", no que concerne ao sustento da casa, haja vista, a garantia do benefício mensal, mantendo além deles mesmos outros familiares como: filhos, netos, nora, genros, pois muitas vezes estes saem em busca de emprego e oportunidades na cidade, não obtêm êxito e retornam ao campo, isso acaba tornando os idosos (as) de assistidos à assistentes.

Para além, o papel da aposentadoria na renda dos idosos (as) é mais do que simplesmente contribuir para o orçamento familiar, ela também é utilizada para custear a produção agrícola, manter a infraestrutura da unidade produtiva. Vale dizer ainda que aposentadoria é por muitas vezes a única renda existente por muitos meses 
do ano, principalmente, porque a agricultura é uma atividade de risco, no que se diz respeito a fatores climáticos (BELTRÃO; OLIVEIRA; PINHEIRO, 2000).

Dados da Síntese de Indicadores Sociais: uma análise das condições de vida da população brasileira afirma que:

Em relação ao rendimento familiar per capita, $75,6 \%$ dos idosos de 60 anos ou mais de idade eram aposentados e/ou pensionistas, em 2015 , e que $69,0 \%$ do rendimento das pessoas nesta mesma faixa etária era proveniente de aposentadoria ou pensão, pode-se dizer que a menor vulnerabilidade monetária dos idosos, e dos familiares que residem com eles, estaria associada ao recebimento destes benefícios (IBGE, 2016 p.32).

Em termos simbólicos, a aposentadoria confere aos idosos (as) a sensação de tranquilidade e segurança, todavia não afasta-os das atividades cotidianas, principalmente, do trabalho na propriedade rural, ao passo que muitas vezes a aposentadoria no meio urbano, retira dos idosos (as) o espaço de sociabilidade proporcionada pelo trabalho deixando um sentimento de vazio e de inutilidade aos mesmos (BRUMER, 2002).

No presente estudo, constatamos que muitos idosos (as) não moravam sozinhos, ou seja, quatro dos oito entrevistados apresentavam em seu quadro familiar a presença de cônjuges, filhos, netos e agregados no mesmo domicílio. Outros três idosos estavam acompanhados apenas por seus/suas parceiros (as), além de uma idosa viúva.

Dados compilados pela PNAD Continua e DIEESE apontam que os idosos (as) estão presentes em 25,1 milhões dos 73,0 milhões de domicílios existentes no Brasil, o que significa que, em $34,5 \%$ dos lares brasileiros, havia, pelo menos, uma pessoa com 60 anos ou mais (DIEESE, 2020).

Estes domicílios se configuram em sua maioria por famílias com novos arranjos familiares e são consideradas famílias ampliadas, este efeito é provocado pelo retorno de filhos à casa paterna/materna, ou os filhos (as) e/ou netos (as) que assumem os pais. Dentre as causas que levam a esses rearranjos familiares podemos citar divórcios, viuvez, gravidez, desemprego e questões de doenças na família (RODRIGUES; SOARES, 2006).

No que tange aos idosos (as) e suas famílias, esses arranjos familiares se ilustram como mosaicos familiares que apresentam disposições diversas que podem apresentar ou não vínculo afetivo, conjugalidade ou parentalidade, dentre outras características. Diante disso, predefinir ou conceituar família é um exercício difícil (BERTUZZI; PASKULIN; MORAIS, 2012).

Para Souza et al. (2012 p.107): o arranjo familiar se configura:

pela formação da família, com laços consanguíneos ou não, convivendo sob o mesmo teto, de forma que o modelo de organização, a função dos papeis familiares e as relações de afeto determinem a configuração a qual está inserida

A presença da família para os idosos (as) é de crucial importância, no que concerne ao bem estar, segurança, apoio e suporte. Além disto a presença da família ampliada (filhos, netos e agregados) pode dar a ideia de continuidade e permanência na terra, já que, o envelhecimento rural coloca em risco à sucessão da terra.

Os assentados estão envelhecendo e, aí, a questão do futuro dos assentamentos passa pela existência de um projeto familiar 
de ficar na terra, de uma estratégia familiar para a continuidade e aprofundamento da experiência produtiva agropecuária dos mais jovens (FERRANTE, BARONE, KURANAGA, 2006 p.37).

Em relação a escolaridade, cinco eram analfabetos, outros três responderam que possuíam apenas os anos iniciais de escolaridade. As falas a seguir evidenciam a questão da escolaridade dos idosos (as):

-Estudei não! Só aprendi a assinar o nome e parei (Idoso 5). -Eu, estudar? Minha filha você acha que naquele tempo tinha esses privilégios? Não tinha não, a única coisa que sei fazer é pegar na enxada...(risos) esses trem de estudos é pra vocês da cidade....meninos novos (Idoso 7).

Em relação aos estudos sobre assentamentos rurais no Brasil, Bergamasco (1997) verificou que para $39,4 \%$ de analfabetos ou possuíam alfabetização incompleta. Já no estado de São Paulo registraram-se $29,7 \%$ de titulares que não chegaram a completar o Ensino Fundamental I (antigo Primário).

Dados mais recentes (INCRA, 2010) mostram que, somando os assentados sem nenhuma escolaridade (analfabetos) e os assentados com escolaridade até a 4은 série do Ensino Fundamental, estes resultam em 59,3 \% das pessoas que residem em assentamentos de reforma agrária pelo país, com baixíssima escolaridade.

No Assentamento Milton Santos, desde 2014, existe o programa de Educação de Jovens e Adultos (EJA), esta iniciativa aconteceu pela parceria entre o MST, a Unicamp e o movimento do coletivo Universidade Popular (UP), vale dizer que a Educadora do EJA é também uma assentada da comunidade, o que possibilitava aos assentados, principalmente, aos mais velhos, ter uma proximidade maior para tirar dúvidas e melhorar o ensino aprendizagem. O EJA do Assentamento Milton Santos tem o perfil de alfabetização e, em sua maioria, quem participa são os idosos (as) que não tiveram a oportunidade de aprender a ler e escrever. Nos depoimentos é perceptível que os idosos (as) falam do EJA, com alegria e gratidão:

-Estudei minha filha, até o segundo ano. Estou na escola ainda. -Estou no EJA agora. Estou aprendendo bem menina, estou aprendendo continha já, dividir, multiplicar...

-É (risos). Estou, estou aprendendo.

-É... tem segunda, terça e quarta.

-Está bom, está muito bom. Tem aluno lá que já vai tirar até carteira de motorista. Não sabia fazer nem uma letra do nome.

-Já, já aprendeu a escrever e já aprendeu ler também, já aprendeu... está aprendendo belezinha.

-Está sendo ótimo! Muito bom, muito bom! Não sei nem como agradecer a professora, né? (Idoso 2).

Estou tão feliz, não sabia ler, sabe moça, as pessoas passam a gente pra trás...quando a gente não sabe ler, agora já posso ler receitas, fazer umas comidas diferentes.

Foi uma coisa muito boa pro Milton Santos...uma oportunidade (Idoso 5).

Pesquisa realizada por Coura (2007) com idosos (as) de áreas rurais que participavam de programas semelhantes, mostram que, a procura e expectativa pela escola está relacionada ao sonho antigo de aprender a "ler e escrever", seja para leitura da Bíblia, simples receitas, rótulos de alimento e até fazer pequenos cálculos. Para este público qualquer evolução e aprendizado é visto como uma ressignificação 
do mundo, busca de autonomia e independência de filhos para ler documentos, para "assinar o próprio nome" e, ao mesmo tempo, a busca de uma condição de vida melhor.

Com o tempo, as expectativas se ampliam. As justificativas para continuar são várias e estão ligadas, sobretudo, às conquistas relacionadas à escola. Sentir-se mais seguro para comentar os acontecimentos atuais, ver beleza na letra de uma música, fazer amigos e se sentir parte de um grupo social são exemplos. Conforme o estudante vai aprendendo e descobrindo coisas novas, percebe que pode conhecer ainda mais. Estudar para esse grupo significa, principalmente, a chance de alargar horizontes (COURA, 2007, p.11).

O trabalho de base idealizado pela Comunidades Eclesiais de Base da Igreja Católica e MST na periferia da Região Metropolitana de Campinas (RMC), as difíceis condições de vida e trabalho das famílias resultaram nas primeiras andanças e movimentações pela conquista da terra em 2005. Os assentados (as) que hoje experimentam o processo de envelhecimento ilustram em suas falas todo episódio de violência, precariedade, conflitos, até a consolidação do Assentamento Milton Santos.

-Desde o primeiro dia que eles fizeram a reunião lá eu estava até trabalhando, cheguei a mulher falou: "Ó, vai ter uma reunião dos sem-terra". Porque desde o Mato Grosso que eu sou louco para pegar (terra). Inclusive eu dei meu nome e fiz um cadastro no correio, mas até hoje estou esperando esse cadastro.

-Lá é 2, 3 alqueires cada um. Eu pensei que aqui iria ser que nem lá, né? Inclusive fiz umas casas para uma turma lá também no assentamento (...). Aí quando eu cheguei a mulher falou, inclusive eu estava trabalhando em Barão Geraldo, a mulher falou que tinha reunião de grupo às quatro. Aí participei de duas. $\mathrm{Na}$ terceira eles já chamaram (...). Comecei em Limeira a ocupar uma granja, ficamos 1 mês e não deu certo...

Ficamos 1 mês, mas lá tinha eu acho que 800 famílias.

-Lá em Limeira. Eu acho que é mais ou menos isso aí. Aí de lá não deu certo, nós fomos para uma fazendinha lá em Limeira mesmo, lá no...esqueci até o nome da fazenda. Aí lá só ficamos 15 dias.

-Deixei a família em casa, trazer meus filhos para sofrerem? Nesse negócio de muda para cá, muda para lá, muda para cá. Não.

-Graças a Deus! Cheguei aqui porque nós conseguimos, mas foi sofrido também, viu? Era vento carregando lona, nós segurando nas lonas, o vento, chuva.... No dia que nós chegamos aqui menina, deu uma tempestade (risos)... Nós chegamos com os caminhões era umas três horas da tarde, dia 23 de dezembro... -Aí fechou o tempo de lá para cá. Um sol quente, de repente soltou um tempo e veio de lá para cá. Aí molhou colchão, molhou tudo, molhou comida.

-Quando eu vim... depois que a minha esposa veio para cá, eu já ó, já tinha mais de um mês que estava aqui. Aí já desmanchou o barraquinho nosso lá e trouxe para cá...

-Aí depois de lá foram divididos os lotes, aí me deram 1.000 metros aqui. Para a gente. Isso aqui era soja, quando tiraram (a) soja, aí dividiram. Aí depois foram cortar os lotes e queriam dar esse meu aqui para os outros, que já estava tudo prontinho, tudo mastigado, eu disse: "Não. Eu vou ficar lá mesmo". Aí que 
tiraram o meu aqui e eu estou aqui até hoje. Graças a Deus! (Idoso 7).

Os idosos (as) pontuaram que quando decidiram se tornar assentados rurais e irem à luta na época, foram taxados como malucos, sofrendo discriminação de parentes, amigos e da sociedade em geral. Os questionamentos eram do tipo: Como vão sair de suas casas? Abdicar do conforto? Morar debaixo da lona preta?

Neste contexto de discriminação e preconceitos, temos que desvelar que a sociedade em geral possui a ideologia de progresso apenas em uma sociedade urbana. Este comportamento talvez esteja relacionado ao poderio midiático que superestima o agronegócio em detrimento a agricultura familiar, além disso não vislumbra o rural como um lugar cheio de identidade, dotado de recursos naturais, produtor de alimentos e de qualidade de vida.

Para reforçar a ideia acima em relação ao preconceito e a discriminação:

As sociedades industriais se urbanizaram e produziram teorias para supervalorização das cidades, em detrimento do rural, que seria o lugar do atraso e da ausência de consciência política. A dificuldade de se reconhecer o valor da zona rural e da produção de alimentos nas formações históricas deriva do poder do urbano sobre o rural, que se formou a partir da Renascença e se consolidou após a Revolução Industrial. Com base nesse histórico, uma vasta gama de preconceitos foi sendo elaborada e chega a atuar como obstáculo epistemológico à compreensão do rural, inclusive em estudos científicos (WHITAKER, 2002 p.35).

Não obstante a todo processo de luta pela terra e seus contratempos, em julho de 2012 quando o Assentamento já estava consolidado e em plena produção, os assentados sofreram ameaça de despejo. Para compreendermos isso, temos de resgatar a história da área que onde se localiza o Assentamento. A área pertencia à família Abdalla, que por dívidas trabalhistas com a União a área foi repassada ao INSS, como forma de pagamento através do Decreto 77.666/1976, em 1976. Assim, a família Abdalla entrou na justiça solicitando a posse da área, alegando que o patrimônio arrecadado era maior que a dívida, a partir desse fato, o juiz emitiu uma liminar de despejo para o INCRA, e, consequentemente para o Assentamento.

Nesse embate, as famílias começaram um processo de resistência e luta contra o despejo, realizando reuniões, acordos com os governos estadual e federal, mas sem sucesso. As famílias, então, em parceria com organizações e entidades elaboraram um dossiê com vários documentos, denunciando a grilagem de terras na região. Foram feitas assembleias abertas ao público, com os representantes do INCRA e da Presidência da República.

No começo do ano 2013 muitas pessoas de movimentos sociais, estudantes, professores universitários, pastorais de igrejas, se mobilizaram e somaram-se ao coletivo na luta pela causa do Assentamento Milton Santos. O suporte para essa mobilização se deu através de notícias veiculadas pela internet, em redes sociais, pela televisão, por rádio e por outros meios de comunicação.

As famílias também ocuparam o Instituto Lula a fim de divulgar a injustiça pela qual estavam passando e fizeram a Campanha "Somos Todos Assentamento Milton Santos" que surtiu efeito, pois a Juíza Federal Louise Filgueira emitiu uma suspensão da liminar de despejo até que fossem julgados os processos da área e determinou o recolhimento provisório do mandado de reintegração de posse expedido em primeira instância (NUNES, 2013). 

seguir:

Esse processo de ameaça de despejo aparece na fala dos idosos (as) a

\begin{abstract}
_Marcou, marcou. Aquela marcou, marcou muito.
Foi bem difícil.

- Você acha, você está com sua casa e de repente não tem mais... inteirinha (...) e tudo (...), mesmo que você pega do jeito que está aqui e quem está num barraquinho de lona, nós estamos no céu aqui dentro! (Idoso 3).

-Olha a história do despejo foi triste demais, menina para onde eu iria com essa idade? Já não aguento trabalhar muito

-Foi muito triste, e como foi!

A turma correu para São Paulo eu fiquei aqui, rapaz. Uma hora apareceu um helicóptero bem aqui em cima... estávamos eu, eu acho que um menino meu e o Léo da Janete. Vi esse helicóptero passando aqui aí eu me apavorei. Aí liguei para São Paulo... Aí foi quando eles ocuparam lá o negócio lá do homem que "maneirou" as coisas, mas eu fiquei com medo (Idoso 7).
\end{abstract}

Embora, este fato seja muito específico, no que se refere ao assentamento Milton Santos, a leitura que se deve fazer é de como este fato despropositado e sem precedentes causou traumas aos idosos (as), pois as falas dos mesmos retratam este momento de angústia e aflição. Principalmente, quando se trata de uma população historicamente marginalizada, que experimenta o envelhecimento recheada de vulnerabilidades desde a idade avançada, a falta de força e disposição para o trabalho, agravados pelo escasso acesso à saúde e a aposentadoria. Na perspectiva social, mudanças e experiências traumáticas como estas na velhice criam uma atmosfera de incertezas e dúvidas acarretando em sentimento de tristeza profunda, angústia, depressão resultando em hospitalizações e até mortes (CABRAL e OLIVEIRA, 2017).

Com relação ao trabalho e a produção, destaca-se que dois idosos (as) produziam hortaliças e entregavam ao Programa de Aquisição de Alimento (PAA). Os outros idosos (as) também produziam seus alimentos, para venda em feiras, venda direta no lote. Estes idosos (as) se mostraram extremamente ativos, pois realizam tarefas importantes dentro do lote como manejo das culturas, reparos e manutenção do lote, manejo e criação de pequenos animais, além da tomada de decisões administrativas e financeiras dentro do lote.

$\mathrm{Na}$ fala dos idosos (as) isso fica explícito:
-Ah, eu cultivo um monte de coisas. Abóbora, caxi, quiabo...e...milho, até melão e melancia eu plantei esse ano.
-Está, agora está tendo água. Agora vou aproveitar e fazer a minha hortinha também, apesar que "catar" a água do poço não pode molhar a horta, não tem bomba, não tem roda d'água (Idoso 3).
-Planto Mandioca, e horta...as mandiocas eu entrego para CONAB, esses tempos estava tudo parado, mas agora parece que a coisa vai caminhar...espero, estou com esperanças (Idoso 8).

Em relação ao acesso a saúde, os idosos (as) residentes em áreas rurais saem em desvantagem, haja vista a questão de distância, isolamento geográfico, a dificuldade com transporte, a infraestrutura das estradas, além da dificuldade financeira. Vale dizer ainda que a atividade laboral no meio rural é pesada, insalubre e às vezes perigosa apresentando riscos diretos à saúde. Deste modo, 
correlacionando acesso à saúde no meio rural, o tipo de trabalho que se realiza, as morbidades crônicas inerentes da velhice, a dificuldade em acesso à aposentadoria $e$ pobreza somam-se a um cenário nada animador (MORAIS; RODRIGUES; GERHARDT, 2008).

Estudos semelhantes que abordaram velhice, saúde e trabalho no meio rural apontam que:

\begin{abstract}
a carência de seguridade social obriga a trabalhar até idades muito avançadas e também por tradição, pois mulheres e, principalmente, os homens devem permanecer trabalhando, porque deixar de trabalhar é sinônimo de inatividade e anúncio de decadência (MORAIS; RODRIGUES; GERHARDT, 2008, p.380).
\end{abstract}

O Posto Médico mais próximo fica a $15 \mathrm{Km}$, o que dificulta muito para os idosos (as), pois o transporte não existe, precisam pedir ajuda a vizinhos ou conhecidos e parentes da cidade. Quanto ao uso de medicação, a maioria (6) informou fazer uso de algum medicamento. Não houve diferença significativa entre homens e mulheres quando perguntados sobre sua saúde, quando comparada com a de outras pessoas de sua faixa etária. A outra questão relevada durante as entrevistas foi a interrupção sem maiores explicações das visitas da equipe multiprofissional de saúde que faziam parte do ESF do Bairro Antônio Zanaga.

Estamos abandonados, não está vindo ninguém mais não referindo-se a Agentes Comunitários de Saúde O postinho é muito longe, o transporte não ajuda moça! Eu vou para Limeira. Remédio eu pego na farmácia pública. Você sabe aquela farmácia lá que a gente faz um cadastro lá e é mais barato?

-No postinho quase não tem remédio" (Idoso 6).

Não vem. Às vezes, às vezes, vem de lá do (Zanardo) $)^{6}$, do postinho.

Faz um levantamento e vai embora também.

Só!'.

-Quando eu quebrei o braço, eu parei de fazer fisioterapia por causa disso. Não tinha condições de eu ir todos os dias, aí abandonei.

Fisioterapia?? Eu vou fazer na enxada. Eu falei mesmo para a moça. Era para fazer duas vezes na semana e até agora nada" (Idoso 4).

Sobre viver e morar no assentamento, as alegrias do envelhecer no campo, as falas a seguir denotam esses sentimentos:

O que faz eu permanecer aqui no Milton Santos? É meu trabalho, que é tranquilo, ninguém perturba. E eu nessa idade já não vou gostar muito de perturbação mesmo, então para mim é uma terapia isso aqui.

Gosto, gosto do meu trabalho. Gosto muito de trabalhar na terra. Ah, eu queria que... comigo... que viesse logo um tempo aí para eles darem pelo menos um papel na mão da gente, para a gente ter uma certeza que a gente estava bem. Estava seguro (Idoso 5) (referia-se ao título de propriedade).

\footnotetext{
${ }^{6}$ Bairro Antônio Zanaga, bairro vizinho ao Assentamento Milton Santos.
} 
Eu graças a Deus... eu agradeço a Deus por estar aqui, porque vou falar a verdade estou no céu. No sossego! As coisas que a gente tem hoje antes não tinha. Eu sempre dependia dos outros, hoje você depende de Deus e basta Deus (para nós vivermos). Só Deus dar saúde para a gente movimentar... De fome eu sei que ninguém morre, eu falei para a mulher, tendo carne e mandioca para a gente comer...

É melhor que na cidade. O sofrimento que eu tinha na cidade, rapaz! Tinha dias que eu acordava às quatro horas da manhã. Para!

O que faz para mim me manter aqui são minhas 'criações' e meu sossego. Aqui parece que eu estou ficando mais novo, você sabia? Eu não tenho preocupação aqui, graças a Deus! A mulher tem hora que esquenta a cabeça, eu... esquentar para quê? Daqui, graças a Deus, só para o cemitério agora (Idoso 8).

Outros elementos de grande simbolismo que foram citados e observados nas falas dos assentados foi à alegria, satisfação, orgulho, felicidade de serem assentados e terem seu pedaço de terra, de possuir e poder produzir seu próprio alimento. Estudos de Sant'Ana et al. (2009), constatam que a conquista da terra evidencia uma esperança de um futuro melhor, além do sonho realizado, envolvendo valores como liberdade, autonomia, felicidade e amor.

Os sonhos e as perspectivas foram notados durante a fala dos assentados/as, e são esses sonhos, anseios, esperanças que os levam a ultrapassarem as adversidades e dificuldades diárias para viver na terra e da terra, para construção de um lote, sítio modelo, dotado de beleza e admiração.

\section{CONSIDERAÇÕES FINAIS}

O presente estudo demonstrou que o grupo de idosos (as) que vive no Assentamento Milton Santos em Americana, sofre vulnerabilidades significativas no acesso à saúde e, principalmente, no acesso à aposentadoria rural. Por outro lado, estes se dizem satisfeitos e mais felizes pela luta e conquista da terra (mesmo com a ameaça de despejo desencadeada no ano de 2012). Notou-se que a aposentadoria é um fator determinante para a permanência no meio rural, pois propicia estabilidade financeira e segurança aos idosos (as) e diminuição das desigualdades sociais. Outro resultado constatado é que os arranjos familiares no campo se compõem por famílias extensas onde duas ou mais gerações convivem juntas e nesse enlace os idosos (as) estão na vanguarda mais assistentes do que assistidos com relação aos filhos (as) e netos (as).

Para além, é de suma importância um novo olhar do serviço de ATER para este crescente público, especialmente no que confere as demandas de políticas públicas e ações inclusivas.

De maneira geral, os idosos (as) apresentaram boas condições de vida e saúde. Todavia, o que se percebeu foi uma carência de políticas públicas e programas de atenção e assistência ao idosos (as) rurais como a criação de espaços ou Centros de Atenção aos Idosos, grupos de assistência em saúde comprometidos, além de outras iniciativas, já tão comuns nos centros urbanos, haja vista a proximidade do Assentamento Milton Santos com os municípios de Americana e Cosmópolis.

Entender a complexidade deste fenômeno do envelhecer no mundo rural nos convida também a um debate sobre a sucessão da terra, o futuro da agricultura familiar, da produção de alimentos e dos assentamentos rurais, o que nos faz refletir 
sobre o processo de reforma agrária brasileiro historicamente negligenciado politicamente.

\section{REFERÊNCIAS}

BELTRÃO, K. I.; OLIVEIRA, F. E. B. de; PINHEIRO, S. S. A população rural e a previdência social no Brasil: uma análise com ênfase nas mudanças constitucionais. IPEA. Texto para Discussão, 759, 2000. Disponível em: http://www.ipea.gov.br/portal/index.php?option=com_content\&view=article\&id=4008 Acesso em: 14 de mar. 2018.

BERGAMASCO, S. M. P. P. B. A realidade dos assentamentos rurais por detrás dos números. Estudos Avançados, São Paulo, v.11, n.31, p. 37-49, 1997.

BERTUZZI D., PASKULIN L. G. M, MORAIS E. P. Arranjos e rede de apoio familiar de idosos que vivem em uma área rural. Texto Contexto Enferm, Florianópolis, v.21, n.1, p.158-166, 2012.

BOSCARDIN, M.; SPANEVELLO, R. M. Dinâmica demográfica da população rural: um estudo de caso na microrregião e município de Frederico Westphalen/RS. Extensão Rural, Santa Maria, v.25, n.2, p.73-91, 2018.

BRASIL. Estatuto do Idoso: Lei Federal no 10.741. Brasília, DF: Secretaria Especial dos Direitos Humanos, 2003. Disponível em: http://www.planalto.gov.br/ccivil_03/leis/2003/L10.741.htm. Acesso em: 14 de fev. 2018.

BRASIL. Ministério da Justiça. Política Nacional do Idoso. Brasília, DF: Imprensa Nacional, 1994. Disponível em: http://www.planalto.gov.br/ccivil_03/leis/l8842.htm. Acesso em: 11 de dez 2017.

BRUMER, A. Gênero e agricultura: a situação da mulher na agricultura do Rio Grande do Sul. Revista Estudos Feministas, Florianópolis, v.12, n.1, p. 205-227, 2002.

CABRAL, M. da L.; OLIVEIRA, I. Trauma social em idade avançada. Saúde e Pesquisa, Maringá, v. 10, n. 3, p. 485-492, 2018.

CAMARANO, A. A.; ABRAMOVAY, R. Éxodo rural, envelhecimento e masculinização no Brasil: panorama dos últimos 50 anos. Rio de Janeiro: IPEA, $1999 . \quad$ Disponível em: https://www.ipea.gov.br/portal/index.php?option=com_content\&view=article\&id=3929 Acesso em: 25 out. 2015.

CARDOSO, M. C. da S.; FERREIRA, M. C. Envolvimento religioso e bem-estar subjetivo em Idosos. Psicologia Ciência e Profissão, Rio de Janeiro, v.2, n.29, p.380-393, 2009.

COURA, I. G. M. A terceira idade na Educação de Jovens e Adultos: expectativas e motivações. 2007 141f. Dissertação (Mestrado em Educação Programa de Pós Graduação em Educação, Universidade Federal de Minas Gerais. Belo Horizonte, 2007. 
DIEESE. Departamento Intersindical de Estatística e Estudos Socioeconômicos. Boletim Especial: quem são os idosos brasileiros. 1 ed. São Paulo: Dieese, 2020. 3p.

FERRANTE, V. L. S. B.; BARONE, L. A..; KURANAGA, A. A. Reforma Agrária e "Desenvolvimento como Liberdade": Uma Nova Visão sobre os Assentamentos Rurais do Estado de São Paulo. Retratos de Assentamentos, Araraquara, v.1, n.2, p.19-44, 2006.

GIL, A. C. Métodos e técnicas de pesquisa social. São Paulo: Atlas, 2007.

GONZAGA, D. de A.; MORAES, M. D; CARVALHO, L. de O.; SANT'ANA, A. L.; OLIVEIRA, V. A. T. de O. A saúde dos idosos em (re) assentamentos de llha Solteira e Pereira Barreto. In: VI SIMPÓSIO REFORMA AGRARIA E QUESTÕES RURAIS, 6. Araraquara, Anais... Araraquara, Uniara, v.1, 2014. p.1-13.

IBGE. Instituto Brasileiro de Geografia e Estatística. Pesquisa Nacional de Amostra por Domicílio - (PNAD) 2013. Rio de Janeiro, IBGE, 2013. Disponível em: http://www.ibge.gov.br/home/estatistica/populacao/trabalhoerendimento/pnad2013/d efa ultsintese.shtm. Acesso em 20 mar. 2018.

IBGE. Instituto Brasileiro de Geografia e Estatística. Sinopse Preliminar do Censo Demográfico 1991. Rio de Janeiro, 1993 - Disponível em: https://biblioteca.ibge.gov.br/biblioteca-catalogo?id=782\&view=detalhes Acesso em: 10 de abr 2017.

IBGE. Instituto Brasileiro de Geografia e Estatística. IBGE - Educa Professores. 2020. Disponível em: https://educa.ibge.gov.br/professores. Acesso em: 20 out. 2020

IBGE. Instituto Brasileiro de Geografia e Estatística. Tábuas Completas de Mortalidade 2016. Disponível em: http://www.ibge.gov.br/home/estatistica/populacao/tabuadevida/2016/default.shtm. Acesso em: 22 set. 2016.

IBGE. Instituto Brasileiro de Geografia e Estatística. Censo Agropecuário Brasileiro - 2017. Rio de Janeiro: IBGE, 2017. Disponível em: https://censos.ibge.gov.br/agro/2017/. Acesso em: 23 abr. 2018.

IBGE. Instituto Brasileiro de Geografia e Estatística. A síntese dos indicadores sociais 2016 - uma análise das condições de vida da população Brasileira". Disponível em: http://www.ibge.gov.br. Acesso em: 28 mar. 2018.

INCRA. INSTITUTO NACIONAL DE COLONIZAÇÃO E REFORMA AGRÁRIA. Pesquisa sobre a qualidade de vida, produção e renda dos assentamentos da reforma agrária. Brasília. Disponível em: http://www.incra.gov.br/index.php/reformaagraria-2/questao-agraria/numeros-da-reforma-agraria/file/1152-pesquisa-qualidadede-vida-nos-assentamentos-2010. Acesso em: 15 abr. 2017.

GOLDFARB, Y. A luta pela terra entre o campo e a cidade: as comunas de terra do MST, sua gestação, principais atores e desafios. 2007 180f. Dissertação (Mestrado em Geografia Humana) Programa de pós graduação em Geografia Humana, Universidade de São Paulo, São Paulo, 2007. 
LEITE, S. P. Impactos dos assentamentos: um estudo sobre o meio rural Brasileiro. São Paulo: UNESP, 2004.

MATHEUS, D. Uma outra concepção de assentamento de reforma agrária: a comuna da terra. 2003. 55f. Trabalho de Conclusão do Curso (Graduação em Serviço Social) - Programa de Graduação em Serviço Social, Universidade Federal de Juiz de Fora

MORAIS, E. P. de; RODRIGUES, R. A. P.; GERHARDT, T. E. Os idosos mais velhos no meio rural: realidade de vida e saúde de uma população do interior gaúcho. Texto Contexto, Florianópolis, v.17, n.2, pp.374-383, 2008.

NUNES, J. S. Produção agroecológica e o fornecimento à alimentação institucional: a experiência do Assentamento Milton Santos, Americana, SP. Curso de Licenciatura em Educação no Campo, Departamento de Instituto de Educação, Universidade Federal Rural do Rio de Janeiro, 2013. 85f. Trabalho de Conclusão de Curso (Licenciatura em Ciências Agrícolas) - Universidade Federal Rural do Rio de Janeiro, 2013.

OLIVEIRA, S. M. de; RODRIGUES, R. B. Envelhecimento em Assentamentos Rurais: Um Olhar sobre a Realidade Atual. In: IV SIMPÓSIO SOBRE REFORMA AGRÁRIA E ASSENTAMENTOS RURAIS, 4., Araraquara, Anais... Araraquara, Uniara, 2010. 20p.

ONU, Organização das Nações Unidas. Em dia internacional, ONU pede fim do preconceito e melhores condições de vida para idosos. $2019 \mathrm{~s} / \mathrm{p}$.

OMS. ORGANIZACION MUNDIAL DE LA SALUD. Salud de las personas de edad: envejecimiento y salud: un cambio de paradigma. 122ª seción. Washington, DC, 2002. $20 \mathrm{p}$.

RICHARDSON, R. J. Pesquisa social, métodos e técnicas. São Paulo: Editora Atlas, 2015.

RODRIGUES, L. de S., SOARES; G. A. Velho, idoso e terceira idade na sociedade Contemporânea. Revista Ágora, Vitória, v.1, n.4, p.01-29, 2006.

SANTOS, S. S. C. Concepções teórico-filosóficos sobre envelhecimento, velhice, idoso e enfermagem gerontogeriátrica. Revista Brasileira Enfermagem, Brasília, v.63, n.6, p. 1035-1039, 2010.

SANT'ANA, A. L, TARSITANO, M. A. A. SILVA, F. C., MODENESE, V. S. O Significado da Terra: o caso dos assentados da Região de Andradina-SP. Retratos de Assentamentos, Araraquara, v. 1, n. 12, p.275-290, 01 jan. 2009. Semestral. Disponível em: http://www.uniara.com.br/arquivos/file/nupedor/revistasretratos/Retratos-v12-2009/conteudo.pdf. Acesso em: 20 mar. 2018.

SILVA, L. H. da. Práticas organizativas do MST e relações de poder em acampamentos/assentamentos do estado de São Paulo. 2007. 212 f. Tese (Doutorado em Ciências Ambientais) - Programa de Pós Graduação em Ciências Ambientais, Universidade Federal de São Carlos, São Carlos, 2007. 
SOUZA, A. B. L.; BELEZA, M. C. M.; ANDRADE, R. F. C. de. Novos arranjos familiares e os desafios ao direito de família: uma leitura a partir do Tribunal de Justiça do Amazonas. Pracs: Revista Eletrônica de Humanidades do Curso de Ciências Sociais da Unifap, Macapá, v.1, n.5, p.105-119, 2012.

ONU. United Nations. Department of economic and social affairs, population division. World Population Prospects: the 2019 revision. New York; 2019, 46p. Disponível em: https://population.un.org/wpp/. Acesso em: 19 de ago. 2020.

WHITAKER, D. C. A. Sociologia rural: questões metodológicas emergentes. Presidente Venceslau: Editora Letras à Margem/CNPq, 2002. 